\title{
Avaliação em teatro: Reflexões a partir das vozes dos alunos
}

\author{
Jean Carlos Gonçalves ${ }^{i}$ \\ Universidade Federal do Paraná, Brasil
}

\begin{abstract}
Resumo
Este estudo, vinculado ao grupo de pesquisa "Linguagem e Educação", da Universidade Federal do Paraná, teve como objetivo compreender os discursos de alunos formandos de um curso superior de teatro sobre a avaliação em processos de montagem teatral em uma universidade catarinense, sul do Brasil. Foram analisados os memoriais de formação em teatro, escritos no último semestre do curso, dos anos de 2007 e 2008. A análise foi realizada pela perspectiva dos estudos de Bakhtin e o Círculo e apontou para diferentes sentidos de avaliação docente, entre eles a relação entre processo e produto, foco deste artigo.
\end{abstract}

Palavras-chave

Avaliação em teatro; Linguagem e educação; Círculo de Bakhtin

\section{Introdução}

Esse texto provém de uma investigação no âmbito de um doutorado, na qual discuti a relação entre as vozes do teatro na educação e as vozes da educação no teatro, na perspectiva dos estudos enunciativos do Círculo de Bakhtin. Uma das questões levantadas na pesquisa foi a complexidade da avaliação de processos artísticos, especificamente os teatrais.

Compreendo que educação, linguagem e teatro estão imbricados, pois as três áreas têm umas a contribuir com as outras em diferentes sentidos. No caso dessa pesquisa, a linguagem contribui para reflexões sobre a educação 
em teatro. É a linguagem, neste trabalho, que possibilita a reflexão sobre a avaliação docente

Analisei, na ocasião, memoriais de formação em teatro, escritos no último semestre do curso de Bacharelado em Teatro-Interpretação, da Universidade Regional de Blumenau, em Santa Catarina, sul do Brasil. Os memoriais de formação em teatro são escritos pelos formandos do curso, se constituindo em documentos oficiais, nos quais acadêmicos falam de suas experiências com a montagem do espetáculo teatral de formatura, realizado como requisito para a diplomação. Os memoriais são escritos com a orientação de um professor e apresentados para uma banca de defesa composta por pelo menos três docentes do curso. Escolhi para análise os memoriais dos anos de 2007 e 2008, pois estes foram os anos em que eu não estive nesta universidade, nem como aluno, nem como professor. Debruceime sobre os enunciados dos sujeitos, de forma a discutir diferentes sentidos para a educação em teatro no ensino superior, a partir de sua escrita.

Nesse artigo, a avaliação é o foco da discussão e o corpus de análise é composto por dois dos memoriais analisados, um de cada ano, escrito sob condições de produção diferentes, pois cada uma das montagens teatrais foi dirigida por um professor diferente, o que deu aos espetáculos características estéticas e linguagens de trabalho distintas.Para tanto, o objetivo desse artigo é compreender a avaliação na esfera do ensino superior em teatro a partir dos enunciados presentes nos memoriais de formação escritos pelos acadêmicos discentes. Como objetivo específico, busco aproximações entre educação, linguagem e teatro e suas implicações para discussões sobre a relação entre processo e produto na educação superior em artes.

O texto está organizado em duas partes centrais: a primeira dedicada a algumas reflexões sobre o pensamento bakhtiniano, teoria escolhida para a análise, e a segunda a olhar para os dados dialogando com a questão específica da avaliação.

\section{0 pensamento bakhtiniano}

As reflexões oriundas dos estudos do Círculo de Bakhtin vêm adentrando cada vez mais o campo de conhecimento em educação. Já não se pensa mais a perspectiva de Bakhtin e seus pares como preciosidade da 
literatura ou da linguagem apenas. O principal interesse do Círculo está nas relações dialógicas, e elas estão em todos os movimentos de interação. A diversidade de vozes que constituem os enunciados dos sujeitos, sua heterogeneidade, a multiplicidade de sentidos e a própria interação social são abordadas, na perspectiva bakhtiniana, como intrínsecas ao ato de viver. Vive-se, logo, dialoga-se.

Para Bakhtin/Voloshinov (2010), a palavra orienta-se em função do interlocutor, e por esse motivo não pertence totalmente ao falante, pois sua materialização é dirigida a alguém. Os sujeitos da enunciação estão inseridos em um ambiente de inter-relação social dentro de um determinado contexto, e é esse contexto que vai definir a situação enunciativa. No caso dessa pesquisa, a materialidade analisada é constituída pelo produto da interlocução presente nos memoriais de formação em teatro, pois a partir do jogo de vozes que compõem os memoriais dos alunos é possível investigar inúmeros sentidos do fazer cênico na universidade.

A palavra sempre procede de alguém e se dirige a alguém, e por isso serve de expressão para relacionar os sujeitos entre si. Através da palavra, defino-me em relação ao outro, isto é, em última análise, em relação à coletividade. Bakhtin/Voloshinov (2010) defende que a palavra é uma espécie de ponte lançada entre mim e os outros.

Em um processo de criação como o teatro, o definir-se em relação ao outro está associado à própria prática artística desenvolvida em conjunto para que um espetáculo atinja objetivos, que vão desde a qualidade técnica dos atores até a apreciação da obra por parte do público. A coletividade, no sentido amplo do termo, implica, necessariamente, interação e interlocução entre sujeitos, com um fim de produção artística. Na universidade (e também em outros meios) esse movimento acontece em uma esfera que possui um caráter educativo, carregando consigo as marcas de heterogeneidade enunciativa peculiar dessa esfera - caso dos enunciados que pretendem rememorar as práticas teatrais que se encontram nos memoriais de formação em teatro.

Segundo Bakhtin/Voloshinov (2010), a linguagem é concebida a partir de um ponto de vista histórico, social e cultural, incluindo a comunicação entre os sujeitos produtores da enunciação. Os sujeitos, socialmente organizados, interagem através de seus dizeres e produzem sentidos por meio deles. E, ao 
falar desse processo, enunciam também de um lugar de autoria que acaba sendo um ato de afirmação de uma ou outra voz que os constituem. Há momentos em que o sujeito sinaliza essas vozes, as revela, e em outros não as cita, mas nem por isso livra-se do fato de seu enunciado ser produto da interação e do jogo de vozes enunciativas.

Esse texto tem como foco os enunciados que falam da forma como o professor participa dos processos de criação teatral. Seu olhar, sua voz, sua postura, sua presença e suas opiniões não passam imunes nos enunciados dos acadêmicos. Embora os enunciados não se refiram à temática da avaliação docente diretamente, eles apontam para as trocas com o professor a partir do sentido de avaliação da prática teatral.

Para Brait (2009), os sujeitos da enunciação deixam marcas do lugar histórico e social de onde enunciam, de sua posição enunciativa; assim, dão pistas ao seu interlocutor, e este vai produzindo também os sentidos que serão responsáveis pela construção de outros enunciados. Esse é o exercício de análise proposto nesse trabalho.

Castro e Picanço (2008), ao escreverem sobre a contribuição do Círculo de Bakhtin para os estudos da linguagem na educação, principalmente no que se refere à questão da formação da subjetividade, sintetizam que, na perspectiva de Bakhtin e o Círculo, "a nossa consciência é multivocal por excelência, pois desde o momento em que nascemos estamos o tempo todo absorvendo o discurso dos outros; isto é, a palavra do outro, o pensamento dos outros, seus costumes e valores" (p. 58). Assim, as vozes dos outros são responsáveis por formar na consciência do sujeito um emaranhado de valores axiológicos e experiências que são acionadas o tempo todo, durante as interações, mesmo que em muitos momentos já não se reconheça a origem primeira dos enunciados. Os autores apontam ainda para a subjetividade como uma fonte de referência dos lugares pelos quais o sujeito passou, do tempo em que viveu, das suas possibilidades econômicas e do contato intelectual que vivenciou. Esse processo está relacionado com a realidade desta pesquisa por propiciar a integração da linguagem com o teatro e a educação; e também sintonizado com a temática proposta nesse artigo, por possibilitar a análise da relação professor $x$ aluno em processos avaliativos como uma relação de valores, axiológica. A relação avaliativa é, desse modo também, uma relação dialógica. Relação permeada por jogos de 
força e pelas vozes de autoridade que se encontram em meio à multivocalidade da sala de aula de teatro. Espaço este que abarca desde os pressupostos do campo educacional até aos artísticos, e no qual os sujeitos interagem como sujeitos de educação e sujeitos do fazer teatral.

Essa pesquisa pretende, desse modo, contribuir para o campo da educação por meio de reflexões sobre a avaliação em processos artísticos. Embora as análises sejam oriundas de condições de produção teatrais, as discussões podem ser também ampliadas para a área de artes, na qual a relação entre processo e produto é sempre um fio de tensão a ser considerado, permeando a interação entre professor e aluno.

\section{Avaliação em cena}

Como a esfera de produção enunciativa é a universitária, um acordo necessário com o leitor é o fato de que as vozes tanto da educação como do próprio teatro encontram-se misturadas nos dizeres dos sujeitos. A esses sujeitos nomino de alunos-atores, pois enunciam de um lugar que é escolar e também artístico, ora como alunos ora como atores de teatro. Vale ressaltar que o Projeto Pedagógico do Curso de Bacharelado em Teatro-Interpretação desta universidade catarinense prevê, na ementa da disciplina Prática de Montagem (na qual os memoriais são escritos), que a mesma implica a montagem de um espetáculo teatral, sob a supervisão de um professor. Da mesma forma, o professor também não escapa de uma dualidade de funções, a de professor e também a de diretor teatral, pois ele está à frente de um processo cênico. $O$ primeiro enunciado a ser analisado já contém alguns desses sentidos para a avaliação:

Utilizando o contexto do espetáculo "A Vida é Sonho", a dinâmica da minha personagem e o olhar externo do professor, criei, com a seqüência que relatei anteriormente, a primeira cena do rei na peça, que é sua entrada no espaço do oráculo (Memorial 1, p. 27).

Esse enunciado sinaliza para considerações sobre a interação, no sentido da importância da participação do professor como observador da ação, como olhar quase que clínico sobre a criação cênica. $O$ acadêmico está a falar de um momento do processo criativo, portanto, do processo de trabalho cênico. Quando ele fala do professor como alguém que olha de fora, que está em um lugar externo e não dentro da ação como co-participante do 
que está sendo criado, há também o sentido de uma voz apta a avaliar, a julgar os processos. É recorrente na prática teatral a presença de um diretor de cena, isto é, a função do professor é a de direção, mas ele não sai do lugar de professor para assumir o lugar de direção. São dois lugares, duas posições, assumidos pelo mesmo sujeito.

$\mathrm{O}$ aluno fala, num primeiro momento, que a partir desse olhar externo do professor ele consegue criar a primeira cena de sua personagem, mas atribui a sua criação também ao contexto do espetáculo e à própria dinâmica da personagem. Bakhtin atribuiria a esse olhar mais um jogo de vozes. 0 aluno silencia quais são as opiniões e as sugestões do professor, resumindo a participação docente ao seu olhar externo. A constituição vocal, que nesse caso é a criação de uma cena, acontece em uma atmosfera heterogênea, que Faraco (2009) aponta como um espaço em que "se pode observar a dinâmica do processo de interação das vozes sociais" (p. 61). Há possibilidades de discussão, inclusive sobre a autoria da cena. Quem é o criador do trabalho? Quem tem méritos quanto ao material criativo que vai para a cena? Em Bakhtin (2006), a autoria única é, na verdade, impossível, pois somos constituídos por diferentes vozes, num emaranhado de valores, axiologias, opiniões, sugestões, julgamentos, que juntos formam uma arena conflituosa arena que, nesta pesquisa, é o próprio ato da criação cênica. Pelo enunciado do sujeito, tal criação acontece sob os olhos atentos do professor, sob sua condução, é pelo filtro da capacidade de julgamento pedagógico do professor e sob sua aprovação que a personagem acontece, aparece, é criada. A autoria cênica é, então, compartilhada. O professor de teatro, ao avaliar, auxilia o aluno a criar sua personagem. Surge aí um sentido para a avaliação no processo teatral: o compartilhar da autoria.

Bakhtin, ao falar sobre o funcionamento da cadeia enunciativa, nos leva a refletir que existem algumas formas evidentes, a partir das quais podemos compreender uma situação dialógica. O dialogismo consiste na interação com o outro e nas vozes que constituem essa interação. Muitas vezes essas vozes podem ser sutis, e outras vezes elas aparecem de forma evidente, como em discussões e polêmicas. Para o autor, o dialogismo implica "A confiança na palavra do outro, a aceitação reverente (a palavra autoritária), o aprendizado, as buscas e a obrigação do sentido abissal, a concordância, suas eternas fronteiras e matizes (mas não limitações lógicas nem ressalvas 
meramente objetais), sobreposições do sentido sobre o sentido, da voz sobre a voz, intensificação pela fusão (mas não identificação), combinação de muitas vozes (um corredor de vozes), a compreensão que completa, a saída para além dos limites do compreensível, etc." (Bakhtin, 2006, p. 327). Essas relações não podem ser reduzidas nem a relações lógicas nem a relações objetais. Aqui se encontram posições integrais, pessoas inteiras, e, portanto, vozes. Por isso, ao analisar enunciados de um sujeito sobre processos educacionais, é preciso considerar que esse jogo de vozes está presente na interação entre professor e aluno. No caso do enunciado analisado, mesmo que o sujeito escreva que o professor não participa efetivamente da ação, a não ser com sua observação, seu olhar, sua direção, a relação com o próprio sentido do ato criativo já é dialógica, pois presume que há alguém responsável pela cena: o professor.

Para Desgranges (2006), "Costuma-se dizer que quando o coordenador do processo [teatral] entra no jogo, perde o olhar exterior, mas se todos os membros do grupo jogam, por que não ele?" (p. 98). Essa pergunta permite a sugestão de que um professor observador, que se posiciona como platéia e observa seus alunos em trabalho, pode estabelecer uma relação dialógica de autoridade, não por uma voz audível, mas por uma postura enunciativa sutil, associada à palavra interiormente persuasiva, da qual fala Bakhtin. Autoridade que lhe é atribuída pelo próprio contexto universitário, e também por sua posição no processo teatral. Desgranges (2006) ainda contribui para essa reflexão, trazendo a seguinte afirmação: "O respeito às criações do grupo, contudo, não significa que o coordenador não possa intervir e sugerir outro rumo quando achar necessário" (p. 98). Compreender tal relação é fundamental para a educação em teatro. A prática teatral implica processos criativos, possibilidade do surgimento de novas autorias, estéticas e maneiras de conceber a cena. A interferência crítica do professor, seja em palavras ou apenas na maneira de olhar e de analisar o que o aluno está realizando em cena, precisa estar aliada a um modelo participativo de exercício pedagógico, no qual o professor seja mais um participante do todo, mais um integrante da criação cênica.

Viola Spolin (2006), ao discutir a autoridade docente e a aprovação/desaprovação que passa pela relação aluno x professor no teatro, chama a atenção para que pensemos a pedagogia da cena com certas 
particularidades: "A expectativa de julgamento impede um relacionamento livre nos trabalhos de atuação. Além disso, o professor não pode julgar o bom ou o mau pois que não existe uma maneira absolutamente certa ou errada para solucionar um problema" (p. 7). A autora, ao discutir os processos de avaliação, aponta para uma importante questão que se aplica a todas as artes, que deve ser considerada pelo professor-artista:

o professor, com um passado rico em experiências, pode conhecer uma centena de maneiras diferentes para solucionar um determinado problema, e o aluno pode aparecer com a forma cento e um que o professor até então não tinha pensado. Isto é particularmente válido nas artes. (Spolin, 2006, p. 7)

Como o processo artístico está também relacionado à autoria e, portanto, ao novo como parte das criações, cabe ao professor estar atento ao que ele mesmo pode descobrir durante o trabalho com seus alunos-artistas.

Para prosseguir nesta discussão, retomo um enunciado a partir do qual é possível ampliá-la: "As aulas de Treinamento se deram de forma dinâmica, agradável, um lugar onde não há o certo e errado (Memorial 2, p. 41)".

Sou sujeito da escola, sujeito que aprende que é preciso ter notas boas, ser bem avaliado, ser bom no que se faz (Spolin, 2006). É na escola que eu, sujeito, aprendo que é o professor quem julga, estabelece conceitos, atribui notas, e por isso o certo e o errado permeiam a vida escolar. Como se explica, então, que no enunciado acima a aula seja enunciada como um lugar onde não há o certo e o errado? Explica-se, pois estas são vozes da educação que circulam socialmente no campo teatral, principalmente no que diz respeito à avaliação. Vozes do teatro e da educação que se misturam, pois mesmo esta montagem está sendo realizada em um contexto educacional, uma universidade.

O que é o certo e o errado numa cena teatral? Como avaliar sem que tal ato passe por escolhas estéticas do próprio professor, ou por direcionamentos pessoais com relação a diferentes linhas de trabalho cênico? O que está em jogo quando há que se avaliar um processo de criação artística que, mesmo objetivando um fim, assume-se sempre como inacabado, inclusive após várias apresentações diante do público? Cabral (2002), ao discutir a avaliação no ensino de teatro, fala que a autonomia do aluno acaba por redefinir os procedimentos tradicionais de avaliação. A autora aborda que a avaliação do desempenho do aluno em teatro está na própria dimensão 
artística do teatro. A experiência teatral torna-se relevante educacionalmente por propiciar linguagens, gestos e possibilidades de engajamento tanto pessoal quanto emocional e que tem no encontro com o outro seu fundamento. Assim, o professor acaba valorizando o processo em detrimento do resultado final, ou produto.

Acontece que a avaliação do processo depende do material criativo que foi atingido até então. Como avaliar sem olhar para o material artístico criado? O próprio processo é cênico e, portanto, feito de cenas que vão sendo criadas. Há uma mostra de processo, não finalizada. Mas há como dizer que um espetáculo pronto esteja realmente pronto quando se fala de teatro? 0 teatro tem uma peculiaridade com relação a outras artes: sua efemeridade, seu ato que é sempre irrepetível. Cada vez que a cena é apresentada, já é outro momento, o que marca sua instabilidade e, portanto, sua possibilidade de alteridade (Bakhtin, 2006). Neste ponto, alguns outros enunciados dos sujeitos dialogam com esta questão:

Além dos apontamentos individuais [a professora] sugeriu que trabalhássemos a evolução das cenas, os momentos de passagem de uma para outra. Que todo o elenco faça os sons iniciais, tanto das cenas do prólogo quanto da entrada de Rosaura. Observa que o espetáculo está totalmente sem ritmo e frio, possui momentos bonitos, mas que podem melhorar muito (Memorial 1, p. 32).

Como já havíamos pesquisado os sons do grupo Barbatuque, criamos a partir deles os sons do prólogo. Mostramos ao professor que nos fez novas proposições (Memorial 1, p. 34).

Em uma das aulas de Interpretação, quando mostramos a cena 2 (Rosaura e Clarin caminhando antes de chegar à torre de Segismundo) para a professora, ela nos propôs a criação de sons vocais para estabelecer o clima de procura instaurado pelas personagens desta cena (Memorial 1, p. 35).

No primeiro enunciado há uma sugestão da professora com relação à cena a ser criada. E logo em seguida ela "observa que o espetáculo está totalmente sem ritmo e frio, possui momentos bonitos, mas que podem melhorar muito". A dimensão aqui é avaliativa, mesmo que não se fale de atribuição de notas ou de pareceres formais. Há uma avaliação ligada à voz docente, à maneira como a professora faz suas observações. São observações sobre etapas do processo. Etapas de um espetáculo em construção. Porém, mesmo que não haja o compromisso de acertar ou errar, é necessário montar o espetáculo e colocá-lo diante do público, e para que 
isso aconteça as cenas precisam "melhorar muito". Poderíamos dizer que há, então, o certo e o errado no tocante à encenação pronta? Se é preciso melhorar, até onde se deve chegar?

Cabral (2002), ao discutir a dicotomia processo x produto, fala que a avaliação de produtos parciais destoa da corrente contextualista no ensino de arte e, ao mesmo tempo, acaba impossibilitando uma avaliação do próprio teatro:

(...) ao fazer teatro, a aprendizagem é em teatro - o tema ou o assunto não seria o mesmo se a forma artística fosse outra. Sem o conhecimento das formas e convenções teatrais é improvável que os alunos possam se beneficiar deste processo de aprendizagem (p. 214).

É a forma artística que viabiliza a expressão e a comunicação de conteúdos em teatro. Para a autora,

quanto melhor o aluno conhecer a forma artística, melhor será sua aproximação ao assunto em foco (...). Assim, se a expectativa é que os alunos aprendam ao fazer teatro, o objeto de avaliação deve ser teatro. Ao formular objetivos expressivos, o professor está abrindo espaço para a performance pessoal e original do aluno, que será a base da avaliação (Cabral, 2002, p. 214).

Pelos outros recortes enunciativos, essa reflexão pode ser ampliada. Em "Mostramos ao professor que nos fez novas proposições" e em "(...) quando mostramos a cena 2 para a professora, ela nos propôs a criação de sons vocais", o ato de mostrar as cenas aos professores parece natural dentro do processo teatral. Parece uma prática recorrente no percurso da montagem do espetáculo. Existe outra forma de diálogo entre a cena que está sendo criada e o professor que não a sua apresentação? Existe possibilidade de dialogar com a cena por outra via que não a própria cena?

Chamo a atenção para a presença da responsividade, discutida por Bakhtin (2006). Ela acontece no ato de mostrar a cena ao professor. Sempre que o sujeito enuncia que o material criativo foi mostrado aos professores, há como resposta outra proposta desses professores, uma contrapartida para que o trabalho continue. A atitude responsiva acontece de forma a que possibilite o diálogo entre a cena e o professor. Entretanto, mesmo que o sujeito enuncie que as interferências docentes acontecem em meio a proposições e sugestões, há vozes de avaliação, pois os encaminhamentos se dão no intuito de que o trabalho melhore. 
Mesmo que, nesse artigo, o foco seja a avaliação docente em teatro, há como pôr em discussão que, se o espetáculo vai a público, o professor também está sendo avaliado por seu trabalho, o que difere a avaliação em teatro de outros campos educacionais. Há um interesse comum de que o espetáculo seja apreciado de forma positiva por parte dos espectadores. E esta avaliação é imediata, tendo como resultado o aplauso. Uma outra avaliação, que fica nesse artigo apenas como provocação a se pensar a complexidade da temática para a educação em teatro.

Em pesquisa sobre a avaliação em teatro, Meneghel e Delagnolo (2010) consideram que "Os instrumentos de avaliação mais utilizados são: provas práticas, atentando para performance (compreendida como capacidade de um desempenho determinado, em disciplinas como interpretação e improvisação teatral) e provas teóricas (questões dissertativas e objetivas)" (p. 110). O caráter prático da avaliação em teatro também deve ser considerado. O desafio, então, consiste em discutir como avaliar uma prática teatral sem que ela seja efetivamente realizada, ou seja, sem que ela se transforme, necessariamente, em produto. A relação entre processo e produto parece, aqui, imbricada, o que faz com que a educação em arte seja colocada em um cruzamento de valores axiológicos, que só pode ser resolvido de forma dialógica, na relação professor $\mathrm{x}$ aluno. As autoras ainda ponderam o fato de que

Uma das peculiaridades da avaliação em Teatro existe no fato das provas práticas, em geral, serem feitas em grupo, o que lhes confere alto grau de complexidade como instrumento avaliativo, por permitirem apontar não só desempenho individual, mas também a capacidade de contribuir/interagir com o grupo, nas mais variadas situações (Meneghel \& Delagnolo, 2010, p. 110).

A prática teatral que está em jogo na montagem de um espetáculo não é individual e, por sua vez, a avaliação também não, dando espaço à complexidade sinalizada na citação acima. Cabe ao professor, então, não somente a orientação dos processos, mas a atribuição de notas; cabe ao professor aprovar ou reprovar os alunos inclusive nas disciplinas práticas, como é o caso da Prática de Montagem. As vozes da educação estão, portanto, impregnadas na prática teatral universitária, o que faz com que os sujeitos, ao enunciarem sobre seus processos de criação, não desvinculem seus dizeres do fato de estarem sendo avaliados num contexto que é, antes de teatral, educacional. 
A avaliação em teatro também precisa lidar, assim, com outro aspecto a ser considerado: a avaliação em grupo. Claro que o fato de os trabalhos serem realizados em grupo em primeira instância pode ser relacionado ao próprio conceito de equipe na comunidade escolar. Tarefas realizadas em equipe fazem parte de diferentes contextos de escolarização, mas o caso do teatro tem seu diferencial, pois praticamente tudo no fazer teatral é compartilhado. A noção de grupo dialoga, assim, com o próprio conceito de Teatro de Grupo, que, embora se movimente por diferentes deslocamentos enunciativos, está quase sempre aliado à divisão de responsabilidades. Avaliar um grupo de teatro, ou uma cena realizada por um grupo, torna-se, então, uma difícil tarefa para o professor, pois, além de toda a subjetividade intrínseca aos processos cênicos, é necessário olhar o grupo e, ao mesmo tempo, as individualidades dos sujeitos que o integram. Avaliar o processo em detrimento do produto está, já, em uma alocação tão subjetiva quanto movediça e, ainda assim, há que se considerar o trabalho do sujeito com relação ao seu grupo e, mais ainda, a relação do que está sendo criado cenicamente com a expectativa do julgamento do público.

\section{Conclusões}

Esse artigo visa contribuir para os estudos de educação em teatro de forma a que as questões apresentadas aqui possibilitem reflexões sobre a avaliação em tal contexto. Uma avaliação da qual o próprio contexto não escapa por ser uma esfera educacional. Embora a avaliação tenha méritos de co-autoria do material cênico criado, sua concretização torna-se quase inatingível sob o ponto de vista de conceitos e notas "justas".

Em teatro, a melhor forma de avaliação acontece em meio ao diálogo. $E$ é aí que sugiro uma avaliação bakhtiniana. Não na perspectiva de uma avaliação em concordância e amabilidade entre os sujeitos apenas, mas uma avaliação dialógica que acontece também entre conflitos, embates vocais, dissensões e dificuldades de relacionamento, tanto entre o grupo e seu professor, quanto entre os próprios alunos-atores.

Embora os sujeitos enunciem que mostram os processos de criação aos professores, suas cenas inacabadas, insisto em defender o fato de que a avaliação em teatro é sempre inacabada, pela própria peculiaridade viva da 
cena, que, mesmo depois de "pronta", sofre alterações e é avaliada de outras formas.

Outra reflexão apontada por esse estudo, e que pode vir a ser explorada, é a avaliação à qual o professor também é submetido. A cena que ele ajuda a criar, que ele dirige, ao ser apresentada passa por outros tipos de avaliação: do público, da própria instituição, de outros alunos do mesmo curso, de outras universidades... A alteridade do professor, ao avaliar e ao ser avaliado, implica diferentes posições a serem ocupadas de forma alternada na sua relação com a cena, relação esta que acontece, já, a partir da ocupação de, no mínimo, duas posições diferentes: a de professor e a de diretor cênico.

A avaliação em grupo possui também seu caráter subjetivo pois não se trata somente de verificar o conhecimento do grupo, mas o crescimento e evolução individual de cada sujeito participante do ato criativo.

Tais questões não têm resposta "certa" ou "errada" nesse artigo, mas ficam como provocações para além do universo educacional do teatro, já que a complexidade da avaliação tem sido alvo de reflexão em diferentes contextos educacionais e em diferentes áreas de conhecimento. Sendo assim, esse texto assume-se como processo, e não como produto, pois as questões levantadas aqui estarão, no encontro com o leitor, novamente em diálogo e, como diálogo, têm o inacabamento como premissa fundamental.

\section{Referências}

Bakhtin, M. (2006). Estética da criação verbal (4ª ed.). São Paulo: Ed Martins Fontes.

Bakhtin, M. (Voloshinov,V.N.) (2010). Marxismo e filosofia da linguagem: Problemas fundamentais do método sociológico na ciência da linguagem (14 ${ }^{\mathrm{a}}$ ed.). São Paulo: Hucitec.

Brait, B. (2009). Bakhtin: Dialogismo e polifonia. São Paulo: Editora Contexto.

Cabral, B. (2002). Avaliação em teatro: Implicações, problemas e possibilidades. Sala Preta, 2, 213-220.

Castro, G., \& Picanço, D. (2008). Dos parcos resultados da educação linguística no Brasil e da importância das relações entre sujeito e linguagem. In M. Schmidt et al., Diálogos e perspectivas de investigação. Ijuí: UNIJUÍ.

Desgranges, F. (2006). Pedagogia do teatro: Provocação e dialogismo. São Paulo: Hucitec. 
92 Jean Carlos Gonçalves

Faraco, C. A. (2009). Linguagem e diálogo: As idéias linguísticas do Círculo de Bakhtin. São Paulo: Parábola Editorial.

Meneghel, S., \& Delagnolo, D. (2010). Avaliação de cursos superiores de música e teatro-interpretação: Desafios para uma prática emancipatória. Dynamis Revista Técnico-Científica, 13(1), 101-112.

Spolin, V. (2006). Improvisação para o teatro. São Paulo: Perspectiva. 
ASSESSMENT IN THEATER: REFLECTIONS FROM THE VOICES OF THE STUDENTS

\begin{abstract}
This study, linked to the research group "Language and Education", Federal University of Parana, aimed at understanding the discourse of senior students of a college of theater on the assessment process in the theatrical assembly in a university in Santa Catarina, southern Brazil. We analyzed the memorials of training in theater, written in the last half of the course, of the years 2007 and 2008. The analysis was performed by the prospect of studies of the Bakhtin Circle and pointed to different directions for the teacher assessment, including the relationship between process and product in education, focus of this article.
\end{abstract}

Keywords

Assessment in theater; Language and education; Bakhtin Circle 
94 Jean Carlos Gonçalves

EVALUACIÓN EN TEATRO: REFLEXIONES DESDE LAS VOCES DE LOS ESTUDIANTES

\section{Resumen}

Este estudio, vinculado al grupo de investigación "Lengua y Educación", de la Universidad Federal de Paraná, ha tenido el objetivo de comprender los discursos de los estudiantes de lo último año de un curso superior de teatro sobre el proceso de evaluación en la producción de teatro universitario en una universidad de Santa Catarina, en el sur Brasil. Se analizaron los memoriales de la formación en el teatro, escritos en el final del curso, de los años 2007 y 2008. El análisis se realizó por la perspectiva de los estudios del Círculo de Bakhtin y se refirió a diferentes instrucciones de la evaluación docente, incluyendo la relación entre el proceso y producto, enfoque de este artículo.

Palabras-clave

Evaluación en teatro; Lengua y educación; Círculo de Bakhtin

Recebido em junho/2012 Aceite para publicação em outubro/2013

i Departamento de Teoria e Prática de Ensino, Universidade Federal do Paraná, Brasil

Toda a correspondência relativa a este artigo deve ser enviada para: Jean Carlos Gonçalves, Universidade Federal do Paraná, Graduação em Produção Cênica, Rua Dr. Alcides Vieira Arcoverde, 1225 (Bloco C), Jardim das Américas,81520-260, Curitiba, PR, Brasil. E-mail: jeancarllos@ufpr.br 